\title{
Research on Improving the Strength of the Cement Stabilized Gravel Soil Basing on Compactness
}

\author{
Yazhen Sun ${ }^{1, a}$, Linjiang $\mathrm{Li}^{\mathrm{b}}$, Bincheng $\mathrm{Gu}^{\mathrm{c}}$ and Rui Guo \\ ${ }^{1}$ School of Transportation Engineering, Shenyang Jianzhu University, Shenyang, China

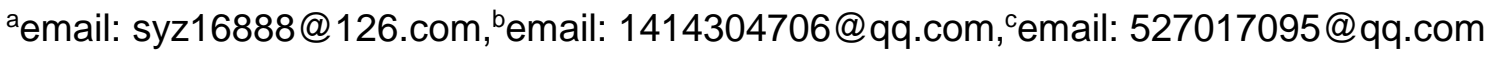 \\ demail: g1248959451@qq.com
}

Keywords: Compactness, Vibration compaction method, 7d unconfined compressive strength,The cement stabilized gravel soil

\begin{abstract}
The pavement subbase is an important part of the pavement structure, and it is also the structural layer which is prone to appear quality problems in the pavement. As the main bearing layer, the pavement subbase plays a connecting role between the subgrade and the pavement. The practical engineering experience shows that strictly control of compaction degree can make the pavement structure to reach stable strength and guarantee the project quality. In this paper, the cement and soil curing agent are used to stabilize the natural gravel soil without sand and gravel area, and the Cement stabilized gravel soil is obtained by the design ratio. The cement stabilized gravel soil specimens are compacted with the vibratory compaction method in different compactness , which is more suitable with the actual construction compaction mechanism. Then the $7 \mathrm{~d}$ unconfined compressive strength of under the hierarchical compaction standard is measured, and the change relationships between the degree of compaction and the strength of the subbase is observed by the analysis of data. Finally, it is concluded that the strength of the subbase increases with the increase of the compaction degree in a certain compaction range, and the strength of the subbase can be improved by increasing the compaction degree.
\end{abstract}

\section{Introduction}

In the overall design, the reasonable selection of the subbase material is the first step to form the strength and other properties of the subbase material [1]. The cement stabilized soil, lime stabilized soil, cement lime consolidated stabilized soil of common pavement subbase types are used. Sometimes, lime industrial slag stabilized soil, graded gravel and grained gravel are also used. From 2003 to 2004, the cement stabilized gravel soil was selected as the subbase through laboratory test and comparative analysis of test section and that was popularized and perfected in the construction of Huaiyang section of Ashen Expressway[2]. Yan Weihua compared and analyzed the dry shrinkage of cement stabilized gravel soil and other kinds of semi-rigid base materials[3]. Huang Wei introduced a kind of the cement stabilized gravel soil and its successful application in highway [4]. Yang Xingwang concluded that the cement stabilized gravel soil was a new type of structure in between the cement stabilized gravel and cement stabilized soil, the cement stabilized gravel soil had the advantage of matching well with the base [5]. In the domestic, the $7 \mathrm{~d}$ unconfined compressive strength is used as the strength index of pavement material and subgrade soil. With the improvement of testing technology in the domestic and the increasing emphasis on highway quality, the $7 \mathrm{~d}$ unconfined compressive strength test has been paid more and more attention by design and construction units and has become one of the references for design and construction. Several typical 
semi-rigid base materials commonly were used in Hunan and the relationship between the different compactness and the compressive strength was analyzed[6]. Den Lu, which the relationship between CBR strength and compaction degree of subgrade soil was obtained [7]. Xia Deliang, which the reference conclusion of the relationship between construction technology and compaction degree of the graded gravel base was drawn[8].

To sum up, in this paper, the cement stabilized gravel soil is used as the base material in the area without sand and gravel. The graded compaction is controlled, vibration compaction method is used to simulate the true state and compaction effect of road construction compaction. Finally, the $7 \mathrm{~d}$ unconfined compressive strength experiment of the specimen is carried out, the relationship between the compaction degree of the cement stabilized gravel soil and the strength of subbase is observed by experimental data.

\section{7d unconfined compressive strength test}

The mixture is formed according to three groups of compaction standards of $94 \%, 96 \%$ and $98 \%$, each group of five specimens and a total of 15 specimens are cured for 7 days and the $7 \mathrm{~d}$ unconfined compressive strength test is carried out [9].

\section{Experimental procedure}

After the oil is applied on the inner wall of the test bucket, the mixture is loaded into the test bucket in three times, and the pressure is gently pressed in each layer. The pressure column of test bucket is exposed to $2 \mathrm{~cm}$ each, the filling procedure is shown in Figure 1 from (a) to (c).

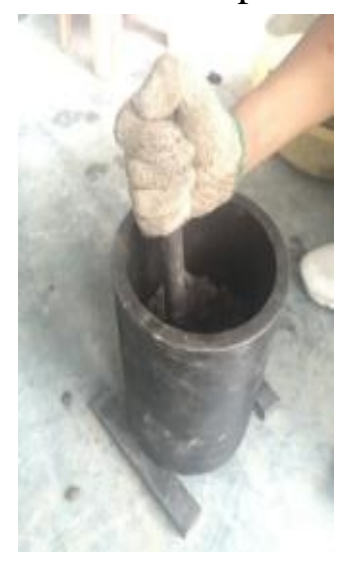

(a)

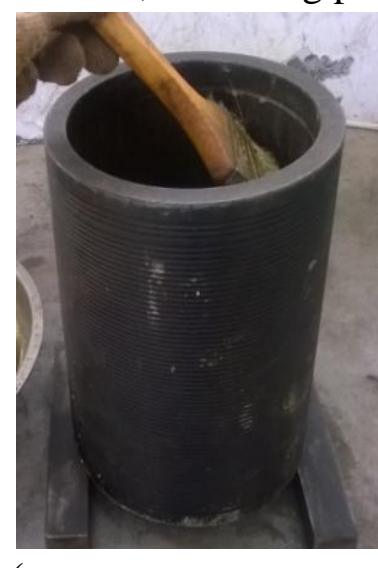

(b)

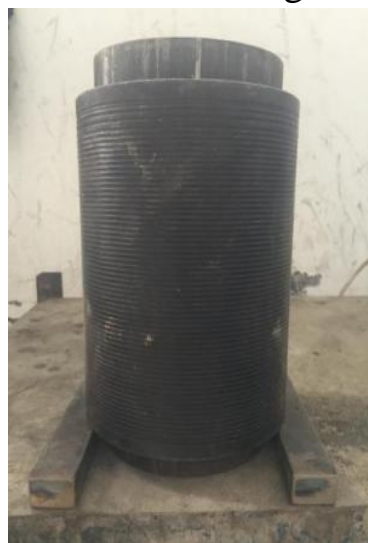

(c)

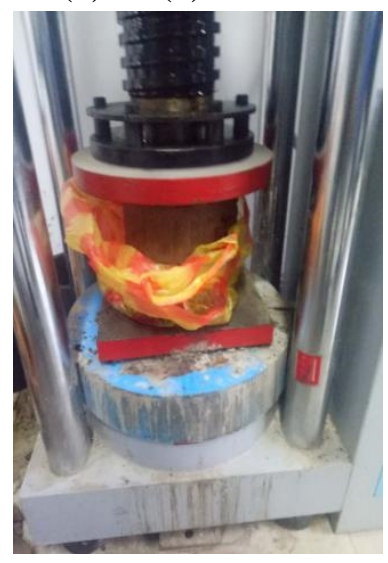

(d)

Fig. 1 Preparation process of specimens

Fig. $27 \mathrm{~d}$ unconfined compressive strength test

The surface vibratory compactor is used to compaction after the completion of filling, so that the compactness standard of the specimen can meet the design requirements. The standard conditions of the sample $\left(25 \pm 2{ }^{\circ} \mathrm{C}\right.$ the temperature of in the south and $20 \pm 2{ }^{\circ} \mathrm{C}$ in the north) are cured for 6 days and soaked for 1 day. After curing, the universal testing machine is loaded at $1 \mathrm{~mm} / \mathrm{min}$ speed until the specimen is damaged and the $7 \mathrm{~d}$ unconfined compressive strength is measured. The $7 \mathrm{~d}$ unconfined compressive strength test are shown in Figure 2, which from Figure (d).

The specimens of unconfined compression strength are tested and calculated $(\mathrm{R}=\mathrm{P} / \mathrm{A}(\mathrm{MPa})$ ) and the diameter and height of the specimens are $150 \mathrm{~mm} \times 150 \mathrm{~mm}$, which the pressure is $0.000057 \mathrm{p}$. In the formula, $\mathrm{P}$ is expressed as damage load and the unit is N. A is expressed as stressed area and the unit is $\mathrm{mm}^{2}$. $\mathrm{R}$ is expressed as unconfined compressive strength and the unit is MPa. 


\section{Experimental calculation}

The value of the calculated strength are shown in the following Table 1.

Table 1 unconfined compressive strength of specimens

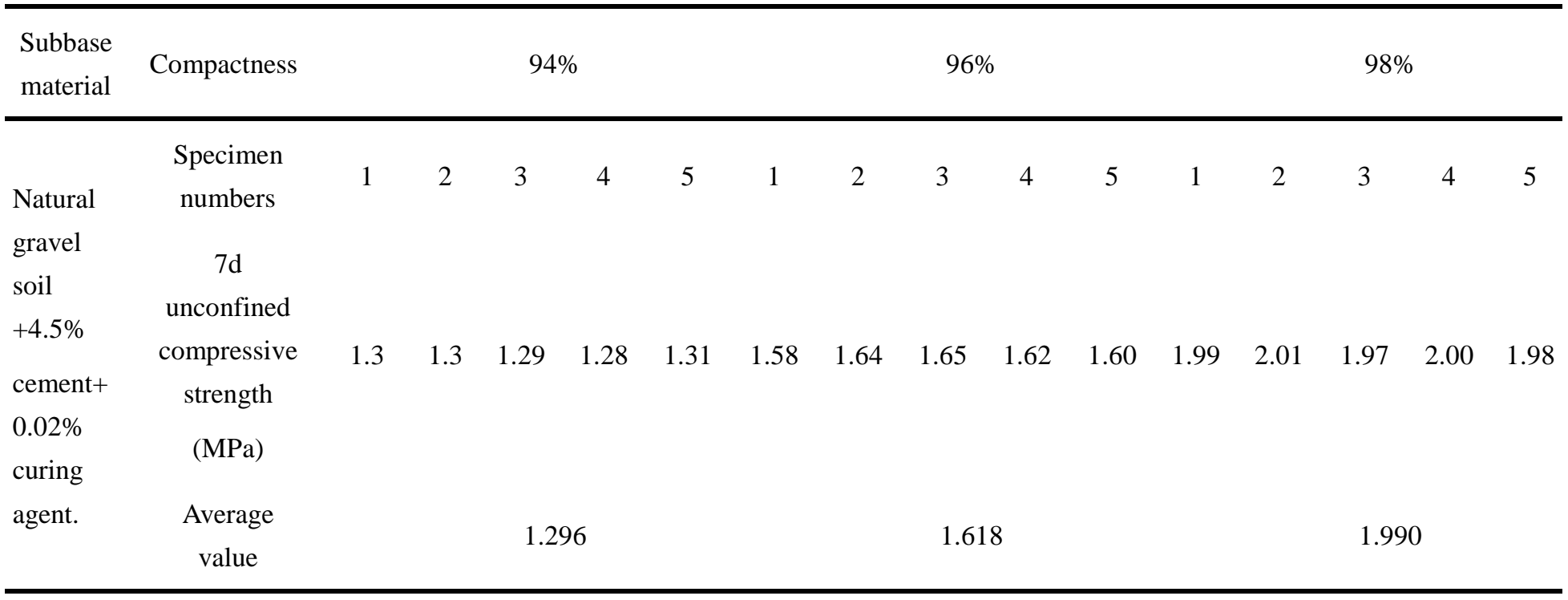

It can be seen from Table 1, when the compaction degree of the specimen is greater than or equal to $96 \%$ of the compaction degree required by the specification, the $7 \mathrm{~d}$ unconfined compressive strength is greater than $1.5 \mathrm{MPa}$, which meets the strength requirements of the subbase. When the compaction degree is less than $96 \%$, the $7 \mathrm{~d}$ unconfined compressive strength of the specimen is less than $1.5 \mathrm{MPa}$.Within the set compaction range, the $7 \mathrm{~d}$ unconfined compressive strength of the specimens increase significantly with the enhance of compaction degree, and it is proved that the key of strength formation is the compactness.

\section{Analysis of the experimental results}

The compaction degree and the $7 \mathrm{~d}$ unconfined compressive strength of three groups of specimens and 15 specimens are analyzed, and the results are shown in following Figure 3 and Figure 4.

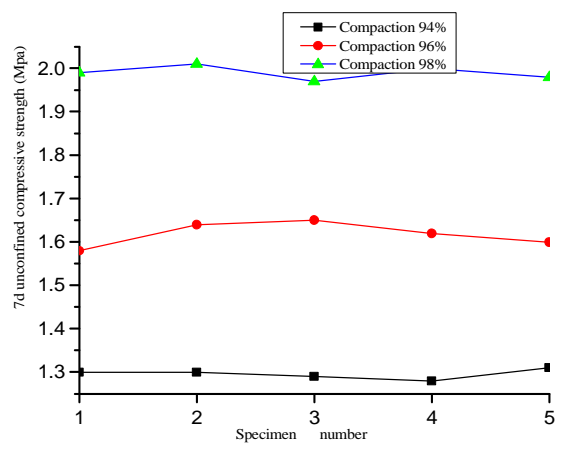

Fig. 3 Compactness of specimens

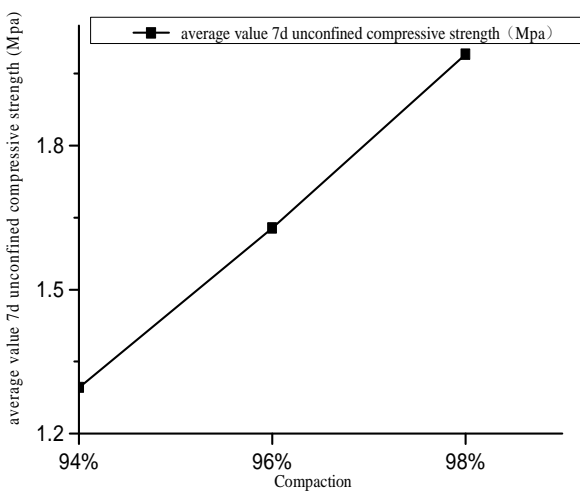

Fig. 4 Average value of the $7 \mathrm{~d}$ unconfined compressive strength

It can be seen from Fig.3, high compaction degree corresponds to high the $7 \mathrm{~d}$ unconfined compressive strength. As shown in Fig.4, the $7 \mathrm{~d}$ unconfined compressive strength values of the cement stabilized gravel soil subbase are increased with the increase of degree of compaction, within the scope of a certain degree of compaction, which suggest that the strength of the cement stabilized gravel soil subbase can be promoted by appropriately increasing the degree of compaction. 


\section{Conclusion}

(1)The specimens are formed under the optimum moisture content in order to achieve the specified compaction degree, and the factors of determining the compaction degree, such as compaction machinery, compaction speed, compaction technology and so on, should be strictly controlled.

(2)The strength of the cement stabilized gravel soil subbase can be improved by increasing of compaction degree. The $7 \mathrm{~d}$ unconfined compressive strength is increased with the increasing of compaction degree in a certain compaction range.

(3)It can be seen from the chart analysis results that the strength of the cement stabilized gravel soil subbase is increased by increasing the compaction degree.

\section{Acknowledgements}

This work was financially supported by the Shenyang science and technology project (17-231-1-26).

\section{References}

[1] JTGT F20-2015,Technical rules for the construction of road surface infrastructure [S], Beijing, people's transportation press(2015).

[2] Gao zhan: Application of cement stabilized gravel soil in pavement base construction [J], Modern transportation technology(2006): 19-23.

[3] Yan weihua: Experimental study on mechanical properties of cement stabilized natural gravel soil [J], East China highway( 2010): 47-50.

[4] Huang wei: Application analysis of cement stabilized gravel soil bottom base [J], Engineering technology,(2010): 84-85.

[5] Yang xinwang: Research on the basic technology of pavement base of cement stabilized gravel soil [J], Construction technology(2013): 99-102.

[6] Liu dengpu:The relationship of between compaction degree and strength of semi-rigid base material, Road and motor (2002): 42-44.

[7] Deng Lou: Experimental study on the relationship between CBR strength and compactness of subgrade soil.Journal of huazhong university of science and technology( 2005): 110-115.

[8] Xia zhiliang: tang jianya, liu yunlan.Experimental study on the relationship between compaction degree and CBR strength of graded gravel base, Highway engineering( 2013):263-265.

[9] JTG E51-2009, Test procedure for stable material of inorganic bond of highway engineering [S],Beijing, people's transportation press(2009). 